\title{
Barriers To Dental Care for Children with Autism Spectrum Disorder- A Pilot Study
}

\author{
Dr. Nithya Annie Thomas ${ }^{1}$, Dr. Priya Shetty ${ }^{2}$, Dr. Sowmya B. ${ }^{3}$, \\ Dr. Venkatesh Kodgi ${ }^{1}$ \\ ${ }^{I}$ (Postgraduate Student, Department of Pedodontics and Preventive Dentistry, \\ A.J. Institute of Dental Sciences, India) \\ ${ }^{2}$ (Reader, Department Of Pedodontics and Preventive Dentistry, A.J. Institute of Dental Sciences, India) \\ ${ }_{3}^{3}$ (Professor \& H.O.D., Department of Pedodontics and Preventive Dentistry, \\ A.J. Institute of Dental Sciences, India)
}

\begin{abstract}
:
Context: Autism spectrum disorder (ASD) is a group of lifelong, neurodevelopmental disorders characterized by severe impairment of social reciprocity, communication and behavior. Complexity in barriers to dental care may be due to behavioral, emotional or developmental disturbances, inability to communicate and financial disincentives.

Objective: To assess the barriers to dental care for children with autism spectrum disorder (ASD).

Materials and method: A cross sectional, case control questionnaire based study was done to evaluate the main hurdles to dental care experienced by children with ASD in Mangalore city. The study group comprised of parents / care takers of children aged 3-12 years with ASD attending special schools in Mangalore city. The questionnaire comprised of closed ended questions, regarding individual barriers while accessing dental care and the proportions of individual barriers to dental care. The data obtained was evaluated using Chi-square test and Fischer's exact test. Significance was deemed at $p<0.001$.

Results: $83.9 \%$ of the respondents reported difficulty in managing the behavior of the children with ASD. Other barriers reported were the child's inability to communicate and dentist's lack of knowledge and training children with ASD.

Conclusions: This research has given an insight into the barriers to dental care experienced by children with ASD in Mangalore city. Access to general practitioners and pediatric dentists should be facilitated by awareness and health policies. Specialized training of dentists and dental students to manage children with special needs should be mandatory.

Clinical implications: This research identified potential barriers to dental care experienced by children with ASD from the perspective of parents/care givers in Mangalore city. This has allowed a greater understanding of the issues that may be faced by this diverse group. It is crucial to gain a better understanding of how these problems could be ameliorated. Dentists should adapt their practices to meet the needs of children with ASD and accept that the needs of children with ASD differ from those of other children.
\end{abstract}

Keywords: Barriers, Dental care, Autism spectrum disorder

\section{Introduction}

The word autism is derived from two Greek words: "autos" which means "self", and "ismos" which means a state of being. Autism Spectrum Disorders (ASDs) are a group of disorders with common lacks in three specific areas: Communication, social interaction and imaginative thought of play. The term "spectrum" discloses the fact that two ASD affected individuals do not behave the same ${ }^{[1]}$.

The Centers for Disease Control and Prevention, 2011 (CDC) defines persons with Autism Spectrum Disorder (ASD) as those who demonstrate "impairments in social, communicative and behavior development, that typically are present before the age of three years and are often accompanied by abnormalities in cognitive functioning, learning, attention and sensory processing" ${ }^{2]}$.

The oral health needs of children with ASD neglected by the parents, because they may face other major problems in upbringing a child with special health needs.

Several studies based on parental reports expressed problems in obtaining dental care for their children with special health care needs (CHSN). Dental treatment need is identified as the greatest neglected health need of persons with developmental disabilities ${ }^{[3]}$. Unmet dental needs can be subdivided into inability to access care and potentially inappropriate care ${ }^{[4]}$. This may be due to various barriers that hinder the parent or the child to avail quality dental treatment. Unresponsiveness to demonstrations and inability to set personal contacts with the dental personnel may hinder professional oral health treatment. Also, the inability to communicate and share 
information using spoken language, actions and eye contact may hinder professional oral health treatments 5 . The child may not be able to express their needs and the parents may be unaware or neglect their dental treatment needs.

A better comprehension of the utilization of dental care of this population and the hurdles that prevent access to dental services is important to identify the opportunities for improving the oral health of children with ASD. Furthermore, health care professionals can work to minimize the difficulties encountered by the families of children with ASD by determining the hurdles faced by them and assimilating effectual management approaches ${ }^{6}$.The primary aim of this study was to evaluate and describe the unmet dental needs and the associated barriers that limit the access to oral health care among children with ASD utilizing a questionnaire based survey.

\section{Procedure}

Following ethical clearance from ethical committee, A.J. Institute of Medical Sciences, Mangalore, Karnataka, a cross sectional questionnaire based study was conducted to evaluate the barriers to dental care in children with ASD. Thirty one parents/ care takers of children with ASD were recruited in the study group and 31 parents/ care takers of healthy, neurotypical children were recruited in the control group respectively. The inclusion criteria were:

- Parents/care takers with children diagnosed with ASD.

- After obtaining informed consent

- Age between 3 and 12 years

- Children attending schools in Mangalore city

The exclusion criteria were:

- Patients with any other medical diagnosis in combination with ASD.

The healthy controls who met the above mentioned criteria were chosen from a normal school to have matched age and sex. All controls were medically fit and healthy.

This questionnaire consisted mostly of closed- ended questions for parents/ caretakers, regarding individual barriers to dental care encountered by their children. The questionnaires were distributed to the parents/ caretakers of the study group and control group through the principals of the schools in Mangalore city. For those who had been to a dentist, dental visit related questions were asked with regard to the child's last dental visit and the main problems faced during their dental visit.

The questionnaire consisted of questions which would examine the association of having unmet dental needs as perceived by parents of children with ASD and also for those children who have been to a dental clinic to which they were to answer with yes or no. The questionnaire distributed in given in Figure 1.

The survey data were analyzed using SPSS software, version 17.0 for Windows. Statistical significance was set at $p<0.001$. It was calculated that the study needed 31 case patients and 31 control patients (power $90 \%$ and confidence level 95\%). Chi square test was used for inter group comparison. The questionnaire was validated and the reliability of the questionnaire was analyzed to be 0.847 using Cronbach's Alpha test.

\section{Results}

Respondents reported that 80.6 percent of ASD children had never visited a dentist or had not visited one within the past year (Table 1).

This is useful information, as frequency of visits to a health care provider has been used in national surveys as an indicator of unmet dental health needs. The American Academy of Paediatric Dentistry recommends routine care at intervals no longer than 1 year, which means that a significant number of ASD children in Mangalore city have unmet dental needs ${ }^{[7]}$.Neurotypical children visiting the dentist were found to be higher $(64.5 \%)$ as compared to children with ASD $(19.4 \%)$ and this association was very highly significant in this study $(\mathrm{p}<0.001)$.

The barriers faced by children/ parents of children with ASD are recorded in the Table 2. Majority of the parents/caretakers in both the study group and control group (80.6\% and $71 \%$ respectively) were not aware of their child's dental needs. However this was not statistically significant ( $p>0.001)$ Parents/ caretakers in the study group cited the child's difficulty to communicate (74.2\%) as the major reason for failing to access dental care for children with ASD and this association was found to be statistically significant $(\mathrm{p}=0.039)$. Speech was the sole method of communication used in the control group. Behavioral issues were cited as an important barrier in providing dental care among autistic children (61.3\%) as compared to neurotypical children (3.2\%). This association was found to be statistically very significant $(\mathrm{p}=0.00)$ Transport to the dentist proved more difficult for $22.6 \%$ of the respondents whose children had a diagnosis of ASD. No one in the control group considered transport as a barrier. Reasons cited were difficulty in transporting child with ASD in public means of commutation. However this association was not statistically significant $(\mathrm{p}=0.005)$ 
Lengthy waiting hours in the clinic for more than 30 minutes proved to be a barrier amongst $29 \%$ of the respondents in the study group. This was statistically very significant $(\mathrm{p}=0.001)$ Financial disincentives were cited to be a barrier for children with ASD as compared to neurotypical children (16.1\%versus 0\%) in our study. However this was not statistically significant $(\mathrm{p}=0.02)$ Difficulty in getting appointment was cited as a barrier for $19.4 \%$ of children with ASD. However this was cited as a barrier by none amongst neurotypical children. The values were highly significant $(\mathrm{p}=0.10)$. Dentist's lack of knowledge and training was cited as a barrier to dental care by $12.9 \%$ of parents of children with ASD. This value was highly significant $(\mathrm{p}=0.000)$.

However, none of the respondents in the control group indicated that transport, financial burden, dentist's skill or child's communication were barriers for their child to access dental services. All these barriers were cited only by parents with autistic children.

Of those children who have attended to dental healthcare services, difficulty in accessing the dental service was found to be higher in parents with autistic children. This value was however not significant $(\mathrm{p}=0.718)$ Transport to the dentist proved to be more difficult for those respondents whose children had a diagnosis of ASD (6.5\%). This study revealed no significant difference between the two groups $(\mathrm{p}=0.554)$.

83.9\% of the respondents with ASD affected children reported difficulty at the reception area when compared to normal children (35.5\%) and this association was statistically very highly significant $(\mathrm{p}=0.00) .12 .9 \%$ reported difficulty at the waiting area. However, both the study group and control group indicated that management of the child was difficult while in the reception area $(16.1 \%)$. However, no statistically significant difference in the 2 groups was found $(\mathrm{p}=0.490) 87.1 \%$ of the study group reported of the dentist's incapability to manage and treat the child.83.9\% of the parents/caretakers cited dentist's incapability to manage child's anxiety prior to treatment. This was statistically very highly significant $(\mathrm{p}=0.000)$.

$19.4 \%$ of the study group respondents expressed the child's negative behavior as a barrier to perform the dental treatment. This was not statistically significant $(\mathrm{p}=0.740) .19 .4 \%$ of normal children showed anxiety or fear before coming to the clinic which was not statistically significant $(\mathrm{p}=0.279)$. Majority of the children in both the groups did not show aggression to sit on the chair. This association was not statistically significant $(\mathrm{p}=0.740)$ The dentist was incapable of managing and treating child with ASD (87.1\%) as compared to neurotypical child $(16.1 \%)$ and this association was highly significant $(\mathrm{p}=0.000)$

Majority of the autistic children were not on recall protocol as compared to normal children and this association was highly significant $(\mathrm{p}=0.000)$ (Table 3$)$.

\section{Discussion}

Amongst the unmet healthcare of children with special health care needs, oral health care and dental treatment ranks the most profound ${ }^{[3,8]}$. Marshall et al reported that up to $25 \%$ of parents experience difficulty in accessing dental care for a child with $\mathrm{ASD}^{[9]}$. This research has examined the barriers to dental care for children with ASD. In the current study, $80.5 \%$ of the children had unmet dental needs, of which the most frequently reported barrier was lack of communication (74.2\%) and behavioral problems (61.3\%).

Parents/ caretakers in our study cited the child's difficulty to communicate as the major reason for failing to access dental care for children with ASD.

Limitations attributed to difficult or unmanageable behaviors hindered children from getting dental care when needed in addition to the commonly reported barriers ${ }^{[6,10]}$. This study reported that the frequency of negative behaviour in $61.3 \%$ of the patients with ASD raising concerns about their ability to access dental care. This was in close relation to findings by Lai et al, who reported frequency of behavioral disturbances in $60 \%$ of these patients ${ }^{[11]}$. Brickhouse et al reported that children with ASD who exhibit behavioral problems are less likely to have regular periodic dental care and subsequently have longer gaps between dental appointments ${ }^{[6]}$.

The literature has reported that dentists experience considerable barriers to providing quality dental care to children with special health care needs. It has been suggested that dental practitioners are unwilling or unable to provide this necessary care due to financial or training constraints. This literature cites lack of dentist's knowledge and training (12.9\%) as a barrier to dental care which is in agreement with studies in the dental literature. Casamassimo reported that as low as $10 \%$ of the practitioners treated children with special needs on a regular basis. A cause of major concern is the fact that dental professionals lack the confidence to accept and treat children with special health care needs. This may be due to lack of training or exposure to children with disabilities during their formal education. Inclusion of formal training in dental curriculum to manage such children and continuing education courses that address the treatment of disabled patients, would improve dental students' competence in working with special needs children ${ }^{[12]}$.

Parents/carers whose children did not access dental care described the problems associated with finding a dentist with the specialised skills involved in treating a child with ASD ${ }^{[4,13,14]}$. It is characteristic that more than $60 \%$ of the general dentists were not willing to give dental care to patients with special needs and mental retardation ${ }^{[15]}$. According to Brickhouse, $15 \%$ of ASD children have never been to a dentist and $19 \%$ were 
unable to receive care when needed. This problem can be alleviated by increasing parent's awareness of the need of early oral health intervention ${ }^{[6]}$.

Our study reported $12.9 \%$ parents/ caretakers reported lengthy waiting time as a barrier to access dental care. This may be due to the fact that there are a lot of trigger factors for negative behavior among children with ASD such as head touching, strange smell or taste, enclosed spaces, bright light, loud noise as they have abnormally enhanced perception of auditory stimuli. Barry et al reported $64.3 \%$ respondents expressed a difficulty in waiting in the waiting room ${ }^{[4]}$. Lai et al reported that $13.8 \%$ of patients with ASD experienced difficulties while waiting for dental treatment ${ }^{[11]}$.

Barry et al cited negative behavior (89.3\%) as a reason for failing access to dental care for children with ASD ${ }^{[4]}$. Review of current research also suggests evidence of behavioral issues as a barrier to dental care (61.3\%). Lai et al also suggested that out of the $12 \%$ children with ASD who had unmet dental needs $60 \%$ in this group cited lack of cooperation by the child as a barrier to accessing dental care.

$22.6 \%$ of the parents/caretakers of the study group reported transport as a barrier. Lai et al reported that $10 \%$ of the parents/ caretakers of children with ASD indicated that transport to dental surgery was a barrier to dental care ${ }^{11}$. This was however in contrast to the findings by Brickhouse et al, who reported that transportation to the dental clinic was not a potential barrier to dental care for this group ${ }^{[6]}$. This difference might be due to the difference in their socioeconomic status.

While evaluating perceived barriers, parents cited lack of dentist's knowledge and training (12.9\%) as a barrier to medical care which is in agreement with studies in the dental literature ${ }^{[4,6]} .25 \%$ of children with ASD had been refused dental treatment according to Brickhouse et al ${ }^{[6]}$. These problems could be ameliorated through improved training opportunities for dentists.

\begin{tabular}{|c|c|c|c|c|c|}
\hline \multicolumn{5}{|c|}{ Table 1- Has the child risited the deatist before? } & \\
\hline & & \multicolumn{2}{|c|}{ Grom } & \multirow[t]{2}{*}{ Total } & \\
\hline & & WitifiSD & NORMAL & & \\
\hline \multirow[t]{2}{*}{ No } & Count & 8 & 11 & 36 & \\
\hline & $y$ & $8.6 \%$ & $35.5 \%$ & $58.1 \%$ & \\
\hline \multirow[t]{2}{*}{ Yes } & Count & 6 & 20 & 26 & \\
\hline & h & $19.4 \%$ & $64.5 \%$ & $41.9 \%$ & \\
\hline \multirow[t]{2}{*}{ Total } & Count & 31 & 31 & 62 & \\
\hline & 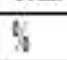 & $100 \%$ & $100.0 \%$ & $100.0 \%$ & 0.00 \\
\hline
\end{tabular}

It was unexpected that parents/ caretakers of both the groups $(16.1 \%)$ reported that the child's behavior becomes unmanageable while waiting.

Waiting in the reception area was reported to be a barrier amongst $12.9 \%$ of children with ASD. This maybe in relation to them not taking prior appointment $(0 \%)$ to attending the dental clinic in order to avoid waiting which would lead to potential behavioral issues in the children.

\section{Conclusion}

The strategies to minimize unmet dental needs should focus on increasing patient cooperation in the dental office, perhaps by utilizing an interdisciplinary team approach as part of the dental health care plan for children with ASD. Future research should examine the specific aspects of dental care by exploring how best to provide a specific dental procedure with a particular child with ASD at a specific developmental epoch along with the associated ASD-related training needs for all health providers.

\section{Figures and Tables}

\begin{tabular}{|l|l|l|l|l|l|l|l|}
\hline & \multicolumn{2}{l}{$\begin{array}{l}\text { Children with } \\
\text { ASD }\end{array}$} & \multicolumn{2}{l|}{ Neurotypical children } & Total & P value \\
\cline { 2 - 8 } & $\mathrm{N}$ & $\%$ & $\mathrm{~N}$ & $\%$ & $\mathrm{~N}$ & $\%$ & \\
\hline $\begin{array}{l}\text { Unawareness among parents of the child's } \\
\text { dental needs }\end{array}$ & 25 & $80.6 \%$ & 22 & $71 \%$ & 47 & $75.8 \%$ & 0.374 \\
\hline Behavioral issues & 19 & $61.3 \%$ & 1 & $3.2 \%$ & 20 & $32.3 \%$ & 0.001 \\
\hline Child's difficulty with communication & 23 & $74.2 \%$ & 0 & $0 \%$ & 23 & $37.1 \%$ & 0.039 \\
\hline $\begin{array}{l}\text { Child being anxious/fearful before coming } \\
\text { to the clinic }\end{array}$ & 3 & $9.7 \%$ & 6 & $19.4 \%$ & 9 & $14.5 \%$ & 0.001 \\
\hline Financial disincentives & 5 & $16.1 \%$ & 0 & $0 \%$ & 5 & $16.1 \%$ & 0.02 \\
\hline Difficulty in accessing dental service & 5 & $16.1 \%$ & 4 & $12.9 \%$ & 9 & $14.5 \%$ & 0.718 \\
\hline Difficulty in travelling to the clinic & 7 & $22.6 \%$ & 0 & $0 \%$ & 7 & $22.6 \%$ & 0.005 \\
\hline
\end{tabular}


Barriers To Dental Care For Children With Autism Spectrum Disorder- A Pilot Study

\begin{tabular}{|l|l|l|l|l|l|l|l|}
\hline Difficulty at the reception area & 26 & $83.9 \%$ & 11 & $35.5 \%$ & 37 & $59.7 \%$ & 0.00 \\
\hline Lengthy waiting time in the clinic & 9 & $29 \%$ & 0 & $0 \%$ & 9 & $14.5 \%$ & 0.001 \\
\hline $\begin{array}{l}\text { Unmanageable behavior of the child while } \\
\text { waiting }\end{array}$ & 5 & $16.1 \%$ & 5 & $16.1 \%$ & 10 & $16.1 \%$ & 1.000 \\
\hline $\begin{array}{l}\text { Lengthy waiting time leading to behavioral } \\
\text { problems }\end{array}$ & 4 & $12.9 \%$ & 7 & $22.6 \%$ & 11 & $17.7 \%$ & 0.319 \\
\hline Child showing refusal to sit on dental chair & 6 & $19.4 \%$ & 5 & $16.1 \%$ & 11 & $17.7 \%$ & 0.740 \\
\hline $\begin{array}{l}\text { Dentist's incapability to manage child's } \\
\text { anxiety prior to treatment }\end{array}$ & 26 & $83.9 \%$ & 9 & $29 \%$ & 27 & $43.5 \%$ & 0.00 \\
\hline $\begin{array}{l}\text { Dentist's incapability to manage and treat } \\
\text { the child }\end{array}$ & 27 & $87.1 \%$ & 5 & $16.1 \%$ & 32 & $51.6 \%$ & 0.00 \\
\hline Dentist's lack of knowledge and training & 4 & $12.9 \%$ & 0 & $0 \%$ & 4 & $6.5 \%$ & 0.00 \\
\hline
\end{tabular}

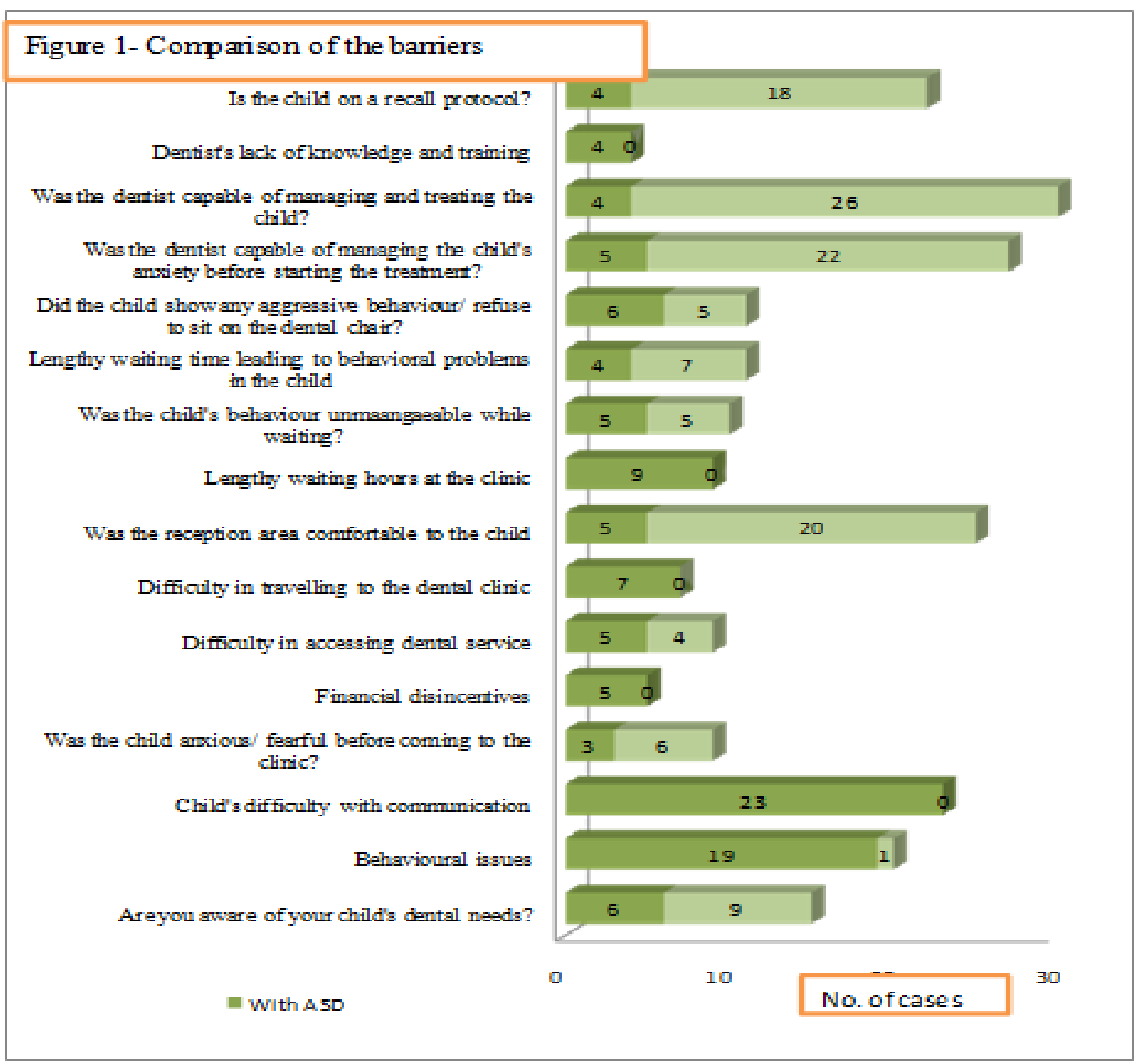

\section{References}

[1]. Autism.net.au [homepage on the Internet]. Australia: Behavioural neurotherapy clinic; 2015 [cited 17 May 2015?]. Available from: http://www.autism.net.au/

[2]. Centers for Disease Control and Prevention. Facts about ASDs. Children assessed by the ASSQ (Autism Spectrum Screening Questionnaire). J. Child Psych. Psychiatry Allied Disciplines. 2011; 4: 167-75.

[3]. Glassman P, Miller CE, Lechowick J. A dental school's role in developing a rural, community-based, dental care delivery system for individuals with developmental disabilities. Spec Care Dentist. 1996;16(5):188-93.

[4]. Barry S, O'Sullivan EA, Toumba KJ. Barriers to dental care for children with autism spectrum disorder.Eur Arch Paediatr Dent.2014. (15):127-134

[5]. Delli K, Reichart P, Bornstein M, Livas $\mathrm{CH}$. Management of children with autism spectrum disorder in the dental setting: Concerns, behavioural approaches and recommendations. Med Oral Patol Oral Cir Bucal. 2013; 18 (6): 862-8.

[6]. Brickhouse TH, Farrington FH, Best AM, Ellsworth CW. Barriers to dental care for children in Virginia with autism spectrum disorders. J Dent Child (Chic). 2009;76(3):188-93.

[7]. The American Academy of Paediatric Dentistry. Reference manual 2007-08. Pediatr Dent 2008;(28):98-107 
[8]. Newacheck PW, Hughes DC, Hung YY, Wong S, Stoddard JJ.. The Unmet Health Needs of America's Children.Pediatrics. 2000;105(4 Pt 2):989-97.

[9]. Marshall J, Sheller B, Mancl L. Caries-risk assessment and caries status of children with autism.Pediatr Dent. 2010;32(1):69-75.

[10]. Lewis C, Robertson AS, Phelps S.. Unmet dental care needs among children with special health care needs: Implications for the medical home. Pediatrics. 2005;116(3):e426-31.

[11]. Lai B, Milano M, Roberts M, Hooper S. Unmet Dental Needs and Barriers to Dental Care Among Children with Autism Spectrum Disorders.J Autism dev disord.2012; 42(7): 1294-303

[12]. Casamassimo PS, Seale NS, Ruehs K. General dentists' perceptions of educational and treatment issues affecting access to care for children with special health care needs. J Dent Educ. 2004;68(1):23-8.

[13]. Johnson CP, Myers SM. Management of children with Autism Spectrum Disorders. Pediatrics 2007;120(5):1162-1182

[14]. DeMattei R, Cuvo A, Maurizio S. Oral Assessment of Children with an Autism Spectrum Disorder Journal of Dental Hygiene 2007;3(81):1-11

[15]. Weil T, Inglehart M. Dental education and dentists attitudes and behavior concerning patients with autism. J Dent Educ. 2010; 74(12): 1294-307.

[16]. Udhya J, Varadharaja MM, Parthiban J, Ila S. Autism disorder (AD): An updated review for paediatric dentists. J Clin Diagn Res. 2014 Feb; 8(2): 275-279.

[17]. Kanner L. Autistic disturbances of effective contact. Nerv Child 1943;2:217-50

[18]. Klein U, Nowak AJ. Autistic disorder: a review for the pediatric dentist. Pediatr Dent. 1998 ;20(5):312-7.

[19]. Murshid, Ebtissam Zakaria. Oral health status, dental needs, habits and behavioural attitude towards dental treatment of a group of autistic children in Riyadh, Saudi Arabia. Saudi Dent J.2005.17(3):132-139

[20]. Nagendra J, Jayachandra S. Autism spectrum disorders: Dental treatment considerations. J Int Dent Med Res 2012; 5 (2):118-121

[21]. Jaber MA. Dental caries experience, oral health status and treatment needs of dental patients with autism.J Appl Oral Sci. $2011 ; 19(3): 212-7$.

[22]. Namal N, Vehit HE, Koksal S. Do autistic children have higher levels of caries? A cross sectional study in Turkish children. J Indian Soc Pedod Prev Dent. 2007;25(2):97-102.

[23]. Khatri A, Sugnani S, Kalra N, Tyagi R. Dental management of Autistic child. JCR 2012;2:1-3

[24]. Capozza LE, Bimstein E. Preferences of parents of children with autism spectrum disorders concerning oral health and dental treatment. Pediatr Dent. 2012;34(7):480-4.

[25]. Dao LP, Zwetchkenbaum S, Inglehart MR. General dentists and special needs patients: does dental education matter? J Dent Educ. 2005;69(10):1107-15

[26]. McIver FT. Access to care: a clinical perspective. In: Mouradian W, editor. Proceedings: promoting oral health of children with neuro-developmental disabilities and other special health care needs: a meeting to develop training and research Agendas, Centre on Human Development and Disability. University of Washington, Seattle, Washington 2001; May 4-5, p. 167-171.

[27]. Al Agili DE, Roseman J, Pass MA, Thornton JB, Chavers LS. Access to dental care in Alabama for children with special needs: parents' perspectives. J Am Dent Assoc. 2004;135(4):490-5

[28]. Klin A. Autism and Asperger syndrome: a review. Rev Bras Biol. 2006;28(1):3-11

[29]. Siegal MD. Dentists' willingness to treat disabled patients. Spec Care Dentist. 1985;5:102-8.

[30]. Tomchek SD, Dunn W. Sensory processing in children with and without autism: a comparative study using the short sensory profile. Am J Occup Ther. 2007;61(2):190-200.

[31]. Rapin I. Autistic children: diagnosis and clinical features. Pediatrics. 1991;87(5 Pt 2):751-60.

[32]. Weil T, Rohr M. Three- to 21-year-old Patients with Autism Spectrum Disorders: Parents' Perceptions of Severity of Symptoms, Oral Health, and Oral Health-related Behavior. Pediatr. Dent. 2012; 34(7): 473-9

[33]. Richa, Yashoda R, Puranik MP. Oral health status and parental perception of child oral health related quality-of-life of children with autism in Bangalore, India. J Indian Soc Pedod Prev Dent. 2014; 32(2): 135-9

[34]. Shapira J, Mann J, Tamari I, Mester R, Knobler H, Yoeli Y. Oral health status and dental needs of an autistic population of children and young adults. Spec Care Dentist. 1989;(9):38-41

[35]. Magoo J, Shetty AK, Chandra P, Anandakrishna L, Kamath PS, Iyengar U. Knowledge, attitude and practice toward oral health care among parents of autism spectrum disorder children. J Adv Clin Res Insights 2015;2:82-86 